\title{
Characteristics Associated with the Dropout of Hypertensive Patients Followed Up in an Outpatient Referral Clinic
}

\author{
Renné Gusmão Busnello, Raquel Melchior, Carlo Faccin, Daniela Vettori, Juliano Petter, \\ Leila Beltrami Moreira, Flávio Danni Fuchs \\ Porto Alegre, RS - Brazil
}

Objective - To determine the characteristics associated with the dropout of patients followed up in a Brazilian out patient clinic specializing in hypertension.

Methods - Planned prospective cohort study of patients who were prescribed an antihypertensive treatment after an extensive initial evaluation. The following parameters were analyzed: sex, age, educational level, duration of disease, pressure level used for classifying the patient, previous treatment, physical activity, smoking, alcohol consumption, familial history of hypertension, and lesion in a target organ.

Results - We studied 945 hypertensive patients, 533 $(56 \%)$ of whom dropped out of the follow-up. The mean age was $52.3 \pm 12.9$ years. The highest probabilities of dropout of the follow-up were associated with current smoking, relative risk of 1.46 (1.04-2.06); educational level equal to or below 5 years of schooling, relative risk of 1.52 (1.11-2.08); and hypertension duration below 5 years, relative risk of 1.78 (1.282.48). Age increase was associated with a higher probability of follow-up with a relative risk of 0.98 (0.97-0.99).

Conclusion - We identified a group at risk for dropping out the follow-up, which comprised patients with a lower educational level, a recent diagnosis of hypertension, and who were smokers. We think that measures assuring adherence to treatment should be directed to this group of patients.

Keywords - systemic hypertension, dropout, treatment

Hospital de Clínicas de Porto Alegre - UFRGS

Mailing address: Renné Gusmão Busnello - Av. Lavras, 341/303 - 90460-040 Porto Alegre, RS, Brazil

English version by Stela Maris C. Gandour
Systemic hypertension is an important risk factor for cardiovascular diseases ${ }^{1-3}$, and it has a high prevalence in the Brazilian adult population. In Porto Alegre, the capital of the State of Rio Grande do Sul in the Southern region of Brazil, approximately $13 \%$ of the adults have systemic hypertension ${ }^{4}$.

Sustained elevated blood pressure levels are related to a higher incidence of morbid events, are mainly associated with atherosclerosis, and may manifest as ischemic heart disease, cerebral stroke, and renal and peripheral vascular diseases $^{5,6}$. On the other hand, in several clinical trials ${ }^{7-9}$, a reduction in fatal and nonfatal cardiovascular events has been associated with the medicamentous treatment of hypertension, mainly with thiazide diuretics and beta-blockers.

In addition, observational studies have shown that most patients with a diagnosis of hypertension have poor adherence to treatment ${ }^{10-14}$, even though we observe that, in the clinical practice, some patients do not even return for regular medical visits. Fuchs et al ${ }^{15}$ have reported a dropout of the regular outpatient clinic follow-up of approximately $45 \%$ in a cohort with hypertensive patients.

The objective of this study was to determine the characteristics associated with the dropout of medical followup of patients treated for systemic hypertension, aiming to identify which patients could potentially benefit from the creation of a system of active follow-up.

\section{Methods}

The population assessed comprised patients enrolled in the cohort of hypertensive patients undergoing followup in the hypertension unit of the Hospital das Clínicas de Porto Alegre. Patients with a diagnosis of hypertension established after an extensive initial evaluation consisting of anamnesis, complete physical examination, standard complementary examinations (laboratory, electrocardiography at rest, and ophthalmoscopy) and serial measures of blood 
pressure were included in the study. The classifying blood pressure used for the diagnosis of hypertension was calculated by the mean of 6 measurements obtained in 3 consecutive medical visits, following the technical recommendations established in the international consensus (Sixth Joint National Committee, 1997) ${ }^{10}$. Characteristics of the sample are shown in table I. Those patients who did not have at least 12 months of follow-up were excluded from the study, as were also a few cases of irregular follow-up with a late return to medical visit.

Dropout of medical follow-up was defined as the noshow to follow-up in a period from 12 to 24 months after the initial evaluation. The control group comprised patients who underwent regular follow-up.

The following variables were analyzed: sex, age $(\leq$ or $>$ 60 years), educational level (schooling $\leq$ or $>5$ years), duration of disease (time since the first diagnosis of hypertension reported by the patient $\leq$ or $>$ years), classifying blood pressure (mean of 6 measurements in 3 consecutive medical visits, during the initial evaluation), previous treatment (use of antihypertensive medication in the past or outpatient clinic follow-up already started, under medication), physical activity (regular physical exercise practice), smoking (current, in the past, or never), alcohol (independent from the amount consumed, current, in the past, or never), familial history of hypertension, and lesion in a target organ (repercussion of hypertension in organs, such as the brain, heart, kidneys, retina, and peripheral vessels).

In the statistical analysis, we used the chi-square test and the logistic regression model. We calculated the relative risk for dropping out of the treatment with the respective $95 \%$ confidence intervals. The significance established was 5\%.

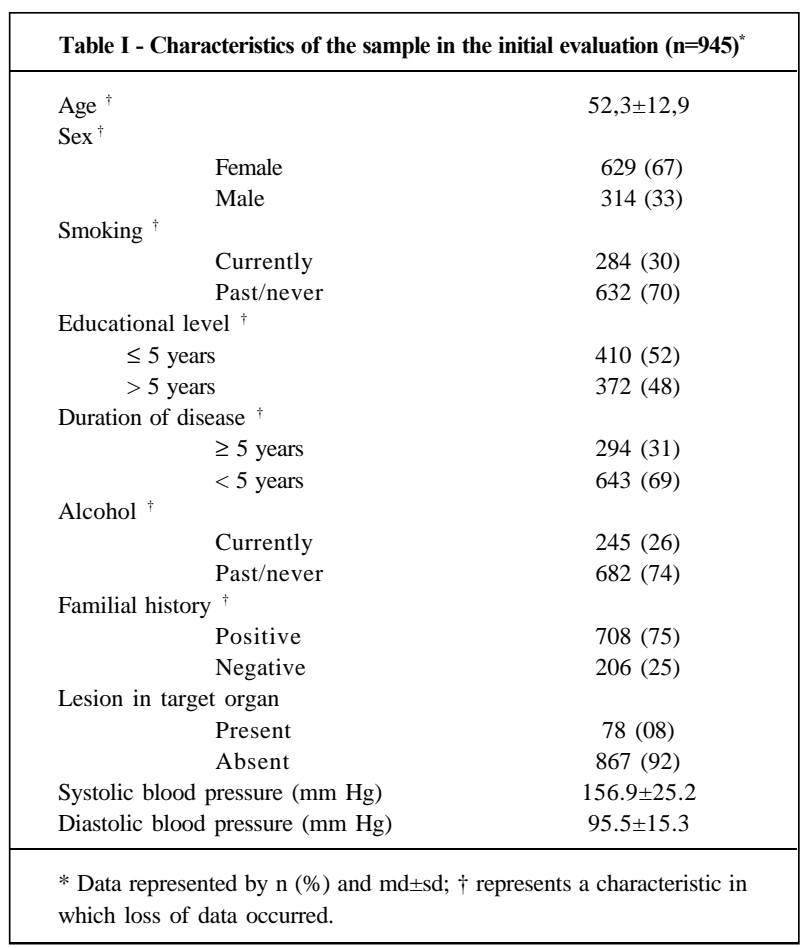

\section{Results}

Out of a total of 945 patients studied, 533 (56\%) dropped out of follow-up and 412 (44\%) remained in regular follow-up for a period of 12 to 24 months. The characteristics of the groups are shown in table II.

In the multivariate analysis carried out with $782(82.7 \%)$ patients, out of all variables studied, 3 were associated in an independent way with a higher probability of dropout, as follows: smoking, schooling $\leq 5$ years, and hypertension diagnosis for less than $<5$ years (table III).

Among current smokers, a dropout rate of $65.5 \%$ occurred, while among nonsmokers or ex-smokers the dropout rate was $52.5 \%$ ( $\mathrm{p}=0.017)$. Patients with schooling $\leq 5$ years

\begin{tabular}{|c|c|c|c|}
\hline \multicolumn{4}{|c|}{$\begin{array}{l}\text { Table II - Characteristics of patients identified in the groups of } \\
\text { dropout and follow-up }\end{array}$} \\
\hline & $\begin{array}{l}\text { Dropout } \\
(\mathrm{n}=533) \\
\mathrm{n}(\%)\end{array}$ & $\begin{array}{l}\text { Follow-up } \\
\qquad \begin{array}{l}(\mathrm{n}=412) \\
\mathrm{n}(\%)\end{array}\end{array}$ & $\begin{array}{c}P \\
\text { Adjusted }\end{array}$ \\
\hline \multicolumn{4}{|l|}{$\mathrm{Age}^{\dagger}$} \\
\hline$\leq 60$ years & $378(59.1)$ & $262(40.9)$ & 0.324 \\
\hline$>60$ years & $138(51.9)$ & $128(48.1)$ & \\
\hline \multicolumn{4}{|l|}{$\operatorname{Sex}^{\dagger}$} \\
\hline female & $345(54.8)$ & $284(45.2)$ & 0.699 \\
\hline male & $186(59.2)$ & $128(40.8)$ & \\
\hline \multicolumn{4}{|l|}{ Smoking ${ }^{\dagger}$} \\
\hline Current & $186(65.5)$ & $98(34.5)$ & 0,017 \\
\hline Past/never & $332(52.5)$ & $300(47.5)$ & \\
\hline \multicolumn{4}{|l|}{ Educational level } \\
\hline$\leq 5$ years & $235(57.3)$ & $175(42.7)$ & 0.025 \\
\hline$>5$ years & $194(52.2)$ & $178(47.8)$ & \\
\hline \multicolumn{4}{|l|}{ Duration of disease ${ }^{\dagger}$} \\
\hline$\geq 5$ years & $143(48.6)$ & $151(51.4)$ & 0.001 \\
\hline$<5$ years & $387(60.2)$ & $256(39.8)$ & \\
\hline \multicolumn{4}{|c|}{ Alcohol consumption ${ }^{\dagger}$} \\
\hline Current & $155(63.3)$ & $90(36.7)$ & 0.076 \\
\hline Past/never & $368(54.0)$ & $314(45.0)$ & \\
\hline \multicolumn{4}{|l|}{ Familial history $^{\dagger}$} \\
\hline Positive & $407(57.5)$ & $301(47.4)$ & 0.187 \\
\hline Negative & $110(53.4)$ & $96(46.6)$ & \\
\hline \multicolumn{4}{|c|}{ Lesion in target organ } \\
\hline Present & $41(52.6)$ & $37(47.4)$ & 0.742 \\
\hline Absent & $492(56.7)$ & $375(43.3)$ & \\
\hline \multicolumn{4}{|l|}{ Blood pressure } \\
\hline$\geq 140 / 90 \mathrm{mmHg}$ & $244(55.3)$ & 197 (44.7) & 0.531 \\
\hline$<140 / 90 \mathrm{mmHg}$ & $263(56.8)$ & $200(43.2)$ & \\
\hline \multicolumn{4}{|c|}{$\begin{array}{l}* \mathrm{P} \text { adjusted for age, sex, smoking, educational level, duration of disease, } \\
\text { alcohol consumption, familial history, lesion in target organ, and } \\
\text { classifying blood pressure; } \dagger \text { represents a characteristic, in which data } \\
\text { loss occurred. }\end{array}$} \\
\hline
\end{tabular}

\begin{tabular}{|c|c|c|}
\hline \multicolumn{3}{|c|}{$\begin{array}{c}\text { Table III - Risk ratio for dropping out of follow-up, significant } \\
\text { variables in the multivariate analysis }\end{array}$} \\
\hline & Relative risk & $\begin{array}{l}\text { 95\% Confidence } \\
\text { interval }\end{array}$ \\
\hline Age & 0.98 & $0.97-0.99$ \\
\hline Smoking & 1.46 & $1.04-2.06$ \\
\hline Educational level $\leq 5$ years & 1.52 & $1.11-2.08$ \\
\hline Duration of disease $<5$ years & 1.78 & $1.28-2.48$ \\
\hline
\end{tabular}


also had a higher risk of dropping out of the follow-up, as compared with those patients with a schooling rate $>5$ years (57.2\% vs $52.2 \%$, $\mathrm{p}=0.025$ ). Hypertensive patients of less than 5 years dropped out of follow-up with a frequency higher than that of those patients with a longer period of disease $(60.2 \%$ vs $48.6 \%, p=0.001)$. The relative risk for dropping out of treatment associated with these characteristics was 1.46 (1.04-2.06) for active smoking, 1.78 (1.11-2.08) for a low schooling rate $\leqslant 5$ years), and 1.98 (1.28-2.48) for the recent diagnosis of hypertension ( $<5$ years). An increase in age ( $>60$ years) represented a reduction in the risk of dropping out the follow-up with a relative risk of $0.98(0.97-0.99)$ (table III).

The remaining characteristics were not significantly associated with the dropout of follow-up.

\section{Discussion}

The treatment of hypertension is always based on changes in lifestyle and may or may not be pharmacological. Regardless of he option, the continuous adherence of the patient to the recommended measures is paramount for obtaining an adequate control of blood pressure.

In addition to the usual difficulties of the adherence to the medical treatment (financial difficulties, noxious effects of the medication, difficulties in accessing the health system, inadequacy of the medical-patient relation), additional characteristic factors of hypertension, such as the usual nonexistence of symptoms in the first 15 to 20 years and the chronicity of the disease, exist.

The interface between efficacy and effectiveness is particularly critical in the treatment of systemic hyperten- sion. Effectiveness, which is evaluated in the actual conditions of treatment, shows unsatisfactory levels of blood pressure control. Much more important than the medical management, which sometimes is a little aggressive, the patient's adherence determines the success of treatment.

A high percentage of dropout of the ambulatory follow-up was identified in our cohort. In addition to several factors inherent to the disease that may explain this fact, we may also cite the great variety in geographical origin of the patients assisted, because at least $35 \%$ of them live in cities other than Porto Alegre.

Even though a loss of 163 patients occurred due to lack of information about certain characteristics, in the multivariate analysis these patients were distributed in a similar manner between the groups of dropout and follow-up.

Smoking seemed to be associated with dropout of medical follow-up, and was also associated with a lower preoccupation with disease prevention and health promotion. In the same way, patients with a recent diagnosis of hypertension did not properly undergo the medical follow-up, perhaps because most of them were previously healthy and asymptomatic. A lower educational level, indicating the social and economical profile, was also related to a high frequency of dropout.

We believe that priority measures should be directed towards the risk group identified in this cohort comprising patients with a lower educational level, a recent diagnosis, and smokers, in order to guarantee adherence to treatment. Medical assistance closer to their dwellings, constitution of support groups, and an active search for those missing the visits may extend the benefit of interventions for controlling hypertension to a larger number of patients.

\section{References}

1. Stamler J, Stamler R, Neaton JD. Blood pressure, systolic and diastolic, and cardiovascular risk: US population data. Arch Intern Med 1993; 153: 593-615.

2. Joint National Committee. The sisth report of the Join National Committee on Prevention, detection, Evaluation and Treatment of High Blood Pressure. Arch Intern Med 1997; 157: 2413-45.

3. Chalmers J, et al. WHO-ISH Hypertension Guidelines Committee. 1999 World Health Organization - International Society of Hypertension Guidelines for the Management of Hypertension. J Hypertens 1999; 17: 151-85.

4. Fuchs FD, Moreira LB, Moraes RS, Bredemeier M, Cardozo SC. Prevalência de hipertensão e fatores associados na região urbana de Porto Alegre. Arq Bras Cardiol 1994; 63: 473-9.

5. Veterans Administration Cooperative Study Group on Antihypertensive Agents. Effects of treatment on morbidity in hypertension. Results in patients with diastolic blood pressure averaging 115 through 129mmHg. JAMA 1967; 202: 116-22.

6. Veterans Administration Cooperative Study Group on Antihypertensive Agents. Effects of treatment on morbidity in hypertension. II. Results in patients with diastolic blood pressures averaging 90 through 114mmHg. JAMA 1970; 213: 1143-52.
7. Neaton JD, Grimm Jr RH, Prineas RJ, et al. Treatment of Mild Hypertension Study: final results (TOHMS). JAMA 1993; 70: 713-24.

8. Prospective Studies Collaboration. Cholesterol, diastolic blood pressure and stroke: 13000 strokes in 450.000 people in 45 prospective cohorts. Lancet 1995; 346; 1647-53.

9. Kaplan NM. Systemic hypertension: mechanisms and diagnosis. In: Braunwald, E. Heart Disease: A Textbook of Cardiovascular Medicine. $5^{\text {th }}$ ed. Philadelphia: WB Saunders Co., 1997; Cap. 26: 807.

10. Burt VL, Curtler JA, Higgins M, et al. Trends in the prevalence, awareness, treatment, and control of hypertension in the adults US population: data from the health examination surveys, 1960 to 1991 . Hypertension 1995; 26: 60-9.

11. Whelton PK. Epidemiology of hypertension. Lancet 1994; 344: 101-6.

12. Tao $\mathrm{S}, \mathrm{Wu} X$, Duan $\mathrm{X}$, et al. Hypertension prevalence and status of awareness, treatment and control in China. Chin Med J 1995; 108: 483-9.

13. Rudd P. Clinicians and patients with hypertension: unsettled issues about compliance. Am Heart J 1995; 130(Pt 1): 572-9.

14. Fuchs FD, Lubianca JF, Moraes RS, et al. Blood pressure effects of antihypertensive drugs and lifestyle modification in a Brazilian hypertensive cohort. J Hypertension 1997; 15: 783-92. 